University of Nebraska - Lincoln

DigitalCommons@University of Nebraska - Lincoln

2005

\title{
Survival and Selection of Migrating Salmon from Capture- Recapture Models with Individual Traits
}

Richard W. Zabel

Northwest Fisheries Science Center

Tyler Wagner

University of Idaho

James L. Congleton

U.S. Geological Survey

Steven G. Smith

Northwest Fisheries Science Center

John G. Williams

Northwest Fisheries Science Center

Follow this and additional works at: https://digitalcommons.unl.edu/usgsstaffpub

Zabel, Richard W.; Wagner, Tyler; Congleton, James L.; Smith, Steven G.; and Williams, John G., "Survival and Selection of Migrating Salmon from Capture-Recapture Models with Individual Traits" (2005). USGS Staff -- Published Research. 651.

https://digitalcommons.unl.edu/usgsstaffpub/651

This Article is brought to you for free and open access by the US Geological Survey at DigitalCommons@University of Nebraska - Lincoln. It has been accepted for inclusion in USGS Staff -- Published Research by an authorized administrator of DigitalCommons@University of Nebraska - Lincoln. 


\title{
SURVIVAL AND SELECTION OF MIGRATING SALMON FROM CAPTURE-RECAPTURE MODELS WITH INDIVIDUAL TRAITS
}

\author{
Richard W. Zabel, ${ }^{1,4}$ Tyler Wagner, ${ }^{2,5}$ James L. Congleton, ${ }^{3}$ Steven G. Smith, ${ }^{1}$ \\ AND JOHN G. WILLIAMS ${ }^{1}$ \\ ${ }^{1}$ Northwest Fisheries Science Center, 2725 Montlake Blvd. E, Seattle, Washington 98112-2097 USA \\ ${ }^{2}$ Idaho Cooperative Fish and Wildlife Research Unit, Department of Fish and Wildlife Resources, University of Idaho, \\ Moscow, Idaho 83844-1141 USA \\ ${ }^{3}$ U.S. Geological Survey, Idaho Cooperative Fish and Wildlife Research Unit, Department of Fish and Wildlife Resources, \\ University of Idaho, Moscow, Idaho 83844-1141 USA
}

\begin{abstract}
Capture-recapture studies are powerful tools for studying animal population dynamics, providing information on population abundance, survival rates, population growth rates, and selection for phenotypic traits. In these studies, the probability of observing a tagged individual reflects both the probability of the individual surviving to the time of recapture and the probability of recapturing an animal, given that it is alive. If both of these probabilities are related to the same phenotypic trait, it can be difficult to distinguish effects on survival probabilities from effects on recapture probabilities. However, when animals are individually tagged and have multiple opportunities for recapture, we can properly partition observed trait-related variability into survival and recapture components. We present an overview of capture-recapture models that incorporate individual variability and develop methods to incorporate results from these models into estimates of population survival and selection for phenotypic traits. We conducted a series of simulations to understand the performance of these estimators and to assess the consequences of ignoring individual variability when it exists. In addition, we analyzed a large data set of $>153000$ juvenile chinook salmon (Oncorhynchus tshawytscha) and steelhead (O. mykiss) of known length that were PIT-tagged during their seaward migration. Both our simulations and the case study indicated that the ability to precisely estimate selection for phenotypic traits was greatly compromised when differential recapture probabilities were ignored. Estimates of population survival, however, were far more robust. In the chinook salmon and steelhead study, we consistently found that smaller fish had a greater probability of recapture. We also uncovered length-related survival relationships in over half of the release group/river segment combinations that we observed, but we found both positive and negative relationships between length and survival probability. These results have important implications for the management of salmonid populations.
\end{abstract}

Key words: behavioral variability; capture-recapture; chinook salmon; individual covariates; mark-recapture; model averaging; Oncorhynchus mykiss; Oncorhynchus tshawytscha; PIT tag; selection; steelhead; survival.

\section{INTRODUCTION}

Animal populations typically exhibit behavioral heterogeneity, and this can confound efforts to understand population dynamics. Capture-recapture experiments, for example, yield information on population abundance, life-stage-specific survival, population growth rate, and selection for phenotypic traits (Seber and Schwarz 2002), but behavioral variability arising from genetic heterogeneity, variability in developmental level, or phenotypic plasticity can lead to differential probabilities of recapture within populations. Studies that ignore differential recapture probabilities can produce

Manuscript received 7 June 2004; revised and accepted 16 December 2004. Corresponding Editor: T. E. Essington.

${ }^{4}$ E-mail: rich.zabel@noaa.gov

${ }^{5}$ Present address: Department of Fisheries and Wildlife, Michigan State University, East Lansing, Michigan 48824 USA. biased estimates of population abundance (MacKenzie and Kendall 2002), selection coefficients (Endler 1986), or survival (Lebreton et al. 1992). Of particular concern is when a phenotypic trait is related to both recapture and survival probabilities, because studies that only have one opportunity to recapture animals cannot distinguish between differential recapture rates and selection. For example, Janzen et al. (2000) obtained different estimates of size-based selection of slider turtles depending on which assumptions they made about non-observed individuals. Thus, understanding the behavioral variability within populations is often critical for estimating population-level attributes such as life-stage-specific survival rates, information that is crucial for managing at-risk populations.

To address this, recent advances in capture-recapture methodology have focused on incorporating individually varying traits into capture-recapture models (Pol- 


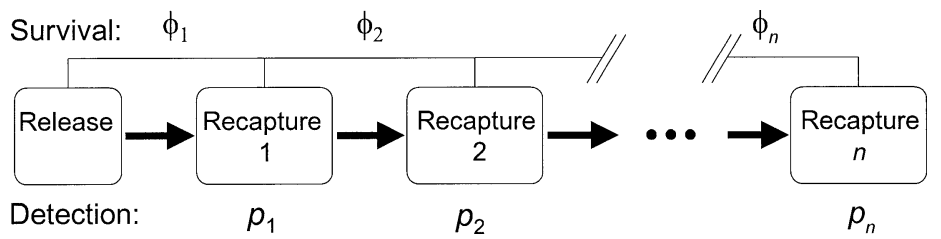

FIG. 1. Schematic diagram of the recapture and survival processes. Note that we cannot estimate $\phi_{n}$ and $p_{n}$ separately, so they are combined such that $\beta=\phi_{n} p_{n}$. lock 2002). When individuals are uniquely identifiable and have multiple opportunities for recapture, it is possible to distinguish differential effects on recapture and survival probabilities. Also, advances in tagging techniques have enhanced our ability to monitor populations. A notable example is the passive integrated transponder (PIT) tag (Prentice et al. 1990a), which lends itself to multiple recaptures of uniquely tagged individuals. Tagging animals with the small (12-mm) tag is relatively benign because "recapturing" individuals often does not require handling: many PIT-tag experiments deploy automatic detectors that record the presence of individuals in both natural habitats (Roussel et al. 2000) and man-made structures (Prentice et al. $1990 b$ ). Worldwide, researchers have used PIT tags to study taxa as wide-ranging as sea urchins (Hagen 1996) and manatees (Wright et al. 1998). In the Columbia River Basin, hundreds of thousands of juvenile salmonids (Oncorhynchus spp.) are PIT-tagged annually and have multiple opportunities for detection as they pass hydroelectric dams during their seaward migration.

Here we examine the importance of incorporating individually varying recapture rates into the estimation of population survival and selection for phenotypic traits. First we present an overview of the underlying capture-recapture models and discuss how to estimate model parameters for a fully specified model. We then develop methods to use results from these models to estimate population-level parameters (survival and selection coefficients), taking into account individually varying survival and recapture probabilities. We conduct a series of simulations to address the following two questions: (1) how well do our estimates of population parameters perform and (2) what are the consequences of ignoring individual variability when it is present? Next, we turn our attention to natural populations where underlying relationships are unknown. Therefore, we first present methods for selecting the best performing models among a suite of alternative models. Finally, as a case study, we analyze an extensive data set based on PIT-tagged juvenile chinook salmon (Oncorhynchus tshawytscha) and steelhead ( $O$. mykiss), both listed as threatened under the U.S. Endangered Species Act. We examine the effect of length at tagging on the probabilities of survival and recapture during migration. In analyzing these data, we also address the physiological and behavioral mechanisms that lead to length-based recapture probabilities, and the management implications of our results.

\section{Methods}

Survival and selection estimation using capturerecapture and individual traits

In typical capture-recapture experiments, individuals are marked and released in a group and have several opportunities for recapture (at least two are necessary to estimate survival). The recapture opportunities are separated temporally or spatially, such as along a migration route. Based on recapture information, capture histories are constructed for each individual. The capture history reflects whether an individual was recaptured (1), not recaptured (0), or removed $(-1)$ for each recapture opportunity. To conduct the type of analysis that we present here, individuals are uniquely tagged and are distinguishable by a measurable trait (or traits) important for determining their behavior and survival.

Two underlying processes determine whether individuals are recaptured: probability of survival between two recapture sites and probability of recapturing an individual, given that it is alive. Thus we incorporate survival and recapture probabilities into a multinomial model of the probabilities of observing all possible realizations of the capture history (Burnham et al. 1987, Lebreton et al. 1992, Skalski et al. 1998). To do this we introduce three terms (based on terminology from Lebreton et al. 1992) for the site-specific survival and recapture probabilities (Fig. 1): $\phi_{j}$ is the probability of fish surviving through the $j$ th encounter segment; $p_{j}$ is the probability of recapturing an individual at the $j$ th recapture event, given that the individual was alive; and $\beta$ is the combined probability of an individual surviving the last encounter segment and being recaptured at the last site, because the data cannot distinguish between these two probabilities. The multinomial model provides a probability density function (pdf) for each potential capture history (by release group), given specified values for the probabilities. When each probability is uniquely specified by release group, this model is often referred to as the Cormack-Jolly-Seber (CJS) model (Cormack 1964, Jolly 1965, Seber 1965). Thus, the CJS model assumes that all individuals in a release group behave identically (that is, they have common survival and recapture probabilities), and that all of the survival and recapture probabilities are independent. Burnham et al. (1987) provide several tests to evaluate these assumptions.

Obviously, if within-population behavioral variability exists, the assumptions are violated. A way to overcome assumption violations is to incorporate behav- 
ioral variability directly into the models. To achieve this, we modify the CJS model (for details, see Hoffmann and Skalski 1995, Pollock 2002, Zabel and Achord 2004) by expressing survival and recapture probabilities as functions of a trait $x$. We use a logit link to ensure that survival and recapture probabilities range from 0 to 1 . For example, the relationship between recapture probability (substitute $s_{j}(x)$ for $p_{j}(x)$ for survival probability) at site $j$ and trait $x$ is

$$
p_{j}(x)=\frac{\exp \left(\alpha_{0, j}+\alpha_{x, j} x\right)}{1+\exp \left(\alpha_{0, j}+\alpha_{x, j} x\right)}
$$

where $x$ is standardized to have zero mean and the $\alpha$ 's are coefficients. If $x$ is not included in the probability, this equation reduces to $p_{j}=\exp \left(\alpha_{0, j}\right) /\left(1+\exp \left(\alpha_{0, j}\right)\right)$, which is a constant.

Model parameters are estimated using maximum likelihood (Mood et al. 1974) by numerically optimizing the log-likelihood function with respect to the parameters. Standard errors are estimated based on numerical approximations of the Hessian matrix (Burnham et al. 1987). The readily available software MARK (White and Burnham 1999) and SURPH (Lady et al. 2001) can conduct these analyses.

\section{Estimating population-level parameters when individuals vary}

Using CJS methodology, estimated population survival between sampling events is simply a model parameter, and thus we simply use the maximum likelihood estimate for this. One element of the CJS population estimates is that $R_{j}$, the number of individuals recaptured at site $j$, is divided by the estimated recapture probability $\left(\hat{p}_{j}\right)$ to estimate the actual number of individuals alive $\left(\hat{N}_{j}\right)$ during sampling event $j$. When individual covariates are included in the recapture probabilities, we can use this same approach, but it is more complicated. We must iterate across all individuals recaptured at site $j$ and divide by the estimated probability of recapturing an individual with attribute $x_{i}\left(\hat{p}_{j}\left(x_{i}\right)\right)$. This gives an estimate of the total number of individuals alive at the recapture site. We divide this by an estimate of the total number of individuals alive during the previous sampling event, which is obtained by multiplying the total number of fish released by the survival estimates between the previous sampling events and subtracting any removed fish:

$$
\begin{gathered}
\hat{N}_{j}=\sum_{i=1}^{R_{j}} 1 / \hat{p}_{j}\left(x_{i}\right) \\
\hat{\phi}_{j}=\frac{\hat{N}_{j}}{\hat{N}_{j-1}-r_{j-1}} .
\end{gathered}
$$

In this equation, $r_{j-1}$ is the number of fish removed at site $j-1$, and site 0 corresponds to the release site. Thus $\hat{N}_{0}$ is the number of fish released, and $r_{0}=0$.
Another population-level attribute is the directional selection coefficient (Endler 1986), defined as follows:

$$
\delta=\frac{\bar{X}_{\mathrm{NEW}}-\bar{X}_{\mathrm{RLS}}}{\sqrt{\operatorname{var}\left(X_{\mathrm{RLS}}\right)}}
$$

where $X_{\mathrm{RLS}}$ is a random variable from the distribution of the trait in the release population, $X_{\mathrm{NEW}}$ is a random variable from the distribution of the trait after selection, and the bar above $X$ designates the mean value. Thus the selection coefficient is determined by the trait-related survival relationship and the initial distribution of the trait.

If we assume that recapture probability is homogeneous in the population, then

$$
\bar{X}_{\mathrm{NEW}}=\frac{1}{R_{j}} \sum_{i=1}^{R_{j}} x_{i}
$$

where $R_{j}$ is the number of individuals recaptured at site $j$. If, however, recapture probability is related to $x$, then

$$
\bar{X}_{\mathrm{NEW}}=\frac{\sum_{i=1}^{R_{j}} \frac{x_{i}}{p_{j}\left(x_{i}\right)}}{\sum_{i=1}^{R_{j}} \frac{1}{p_{j}\left(x_{i}\right)}} .
$$

Once again, the differential capture probability in the denominator of each summation inflates each observed individual to reflect the expected number of individuals of that size alive during the $j$ th sampling event.

\section{Simulations}

We had two motivations for conducting the simulations. First, we assessed the efficacy of Eqs. 2 and 5 as means of incorporating individual heterogeneity into population-level estimates of survival and selection. Second, we wanted to determine under which scenarios we expect to see biases in population-level estimates when existing individual heterogeneity is ignored. Because these biases are likely to vary with sample size, parameter values, and complexity of the system, fully understanding their behavior is beyond the scope of this paper. Instead, we focused on establishing the most important effects. Accordingly, we adopted a simple system in which we set the number of released individuals at 1000 , and individuals had two opportunities for recapture. Thus we could simulate trait-based effects for the recapture probability, $p_{1}(x)$, the survival probability, $\phi_{1}(x)$, and the combined survival and recapture probability at the second recapture site $\beta(x)$.

We assumed that trait $x$ in the population was normally distributed with zero mean and variance $=1.0$. We set each of the effects parameters $\left(\alpha_{x}\right)$ to -0.35 , 0.0 , or 0.35 , with the magnitude of the trait effect chosen such that individuals with the 97.5th percentile value of the trait had approximately twice the probability of survival or recapture as individuals from the 2.5 th percentile. We set $\alpha_{0}$ for $\phi_{1}(x)$ to 2.0 , so an in- 
dividual with mean $x$ had a survival probability through the first recapture site of $0.88, \alpha_{0}$ for $p_{1}(x)$ to 1.0 , so an individual with mean $x$ had a recapture probability at the first site of 0.73 , and $\alpha_{0}$ for $\beta(x)$ to 0.0 , so an individual with mean $x$ had a combined probability of survival and recapture at the second site of 0.5 .

The first step of each simulation was to simulate each individual's capture history based on the underlying survival and recapture processes. To do this we first randomly assigned each individual a value of trait $x$. Then we determined the probabilities $p_{1}(x), \phi_{1}(x)$, and $\beta(x)$ and repeatedly drew from a binomial distribution to determine each individual's fate. Based on these simulated data, we first calculated CJS survival estimates and selection coefficients based on Eq. 4. We then estimated model parameters (the $\alpha_{0}$ and $\alpha_{x}$ parameters for each of the $\phi_{1}, p_{1}$, and $\beta$ terms) for each parameter that was set different from zero, and used these parameters to estimate population survival and selection coefficients using the individual covariate method, Eqs. 2 and 5, respectively. For each run of the simulation, we compared these alternative estimates to the true population survival and selection coefficients (which were calculated in each simulation), and determined the differences (a negative difference indicated that the estimated value was less than the true value). Based on 1000 simulations for each scenario, we calculated the mean and standard deviation of the differences for each estimation method. We considered an estimate to be biased if the mean difference between the estimate and true value was $>0.001$ or $<0.001$, because the means of the true values varied across simulations by this amount.

\section{Model selection}

One of the key questions in analyzing capture-recapture data from natural populations is whether to include the trait $x$ in the various survival and recapture probabilities. Answering this question involves model selection. Because capture-recapture models are often complex, and because several alternative models might perform similarly, most capture-recapture studies now use AIC (or one of its variants) for model selection (Seber and Schwarz 2002), as opposed to more traditional methods such as likelihood ratio tests. Further, there is a trend in capture-recapture studies toward selecting a suite of well-performing models (Johnson and Omland 2004) as opposed to choosing a single "best" model. Model averaging (Burnham and Anderson 2002) is then used where all the selected models contribute to the final parameter estimates (for ecological examples, see MacKenzie and Kendall 2002, Mazerolle 2003, McPherson et al. 2003). An advantage of model averaging is that model uncertainty is incorporated into the estimation of model parameters (MacKenzie and Kendall 2002, Johnson and Omland 2004). We adopted this approach because it is particularly well-suited to our case study that follows.
The first step is to run all possible combinations of trait $x$ included or not for each of the model terms $\left(2^{2 n-1}\right.$ possible combinations, where $n$ is the number of recapture sites). Clearly this is intractable if there are many recapture opportunities, but simplifying assumptions such as identical relationships across sites can reduce the number of models. $\mathrm{AIC}_{\mathrm{c}}$ (AIC corrected for sample size; Burnham and Anderson 2002) is used to weight each model $i$ according to

$$
w_{i}=\frac{\exp \left(-\Delta_{i} / 2\right)}{\sum_{j=1}^{M} \exp \left(-\Delta_{j} / 2\right)}
$$

where $M$ is the number of alternative models, and $\Delta_{i}$ is the difference in $\mathrm{AIC}_{\mathrm{c}}$ between model $i$ and the one with the lowest $\mathrm{AIC}_{\mathrm{c}}$. Note that the denominator normalizes the weights so that they sum to 1.0. Models are included one by one, beginning with the best-fitting one, until the sum of the weights is $>0.95$ (or some other predetermined value), and then are renormalized so that weights of the selected group of models sum to 1.0 .

Once the models are selected, the next step is to estimate model-averaged parameters and standard errors. Model-averaged parameter estimates are weighted means across all selected models in which the parameter is included. If we use $\theta$ to generically signify any parameter, then the model-averaged estimate of $\theta$ is

$$
\hat{\theta}_{a}=\sum_{i=1}^{S} w_{i} \hat{\theta}_{i}
$$

The summation is across all selected models that contain the parameter, $\hat{\theta}_{i}$ is the estimate of $\theta$ from the $i$ th model, and, again, the weights are renormalized to sum to 1.0. In this study, we are interested in estimating length relationships, so we only include the $\alpha_{0}$ 's in the selected set when they are part of a length relationship and thus have a corresponding $\alpha_{1}$. The standard errors associated with each parameter are estimated as

$$
\operatorname{SE}\left(\hat{\theta}_{a}\right)=\sum_{i=1}^{S} w_{i} \sqrt{\operatorname{var}\left(\hat{\theta}_{i}\right)+\left(\hat{\theta}_{i}-\hat{\theta}_{a}\right)^{2}}
$$

(Burnham and Anderson 2002). Note that the estimated standard error reflects variability associated with each individual estimate and model uncertainty, reflected by the second term in the square root. The $95 \%$ confidence intervals about the estimated relationships (using recapture probability as an example) are

$$
p_{j}(x)=\frac{\exp \left(\alpha_{0, j}+\alpha_{x, j} x \pm z_{0.975} \mathrm{SE}\right)}{1+\exp \left(\alpha_{0, j}+\alpha_{x, j} x \pm z_{0.975} \mathrm{SE}\right)}
$$

where $z_{0.975}$ is the 97.5 th percentile of the $z$ distribution, and the standard error (SE) is defined as

$$
\mathrm{SE}=\sqrt{\operatorname{var}\left(\alpha_{0}\right)+x^{2} \operatorname{var}\left(\alpha_{x}\right)+2 x \operatorname{cov}\left(\alpha_{0}, \alpha_{x}\right)}
$$

(Hosmer and Lemeshow 2000). 


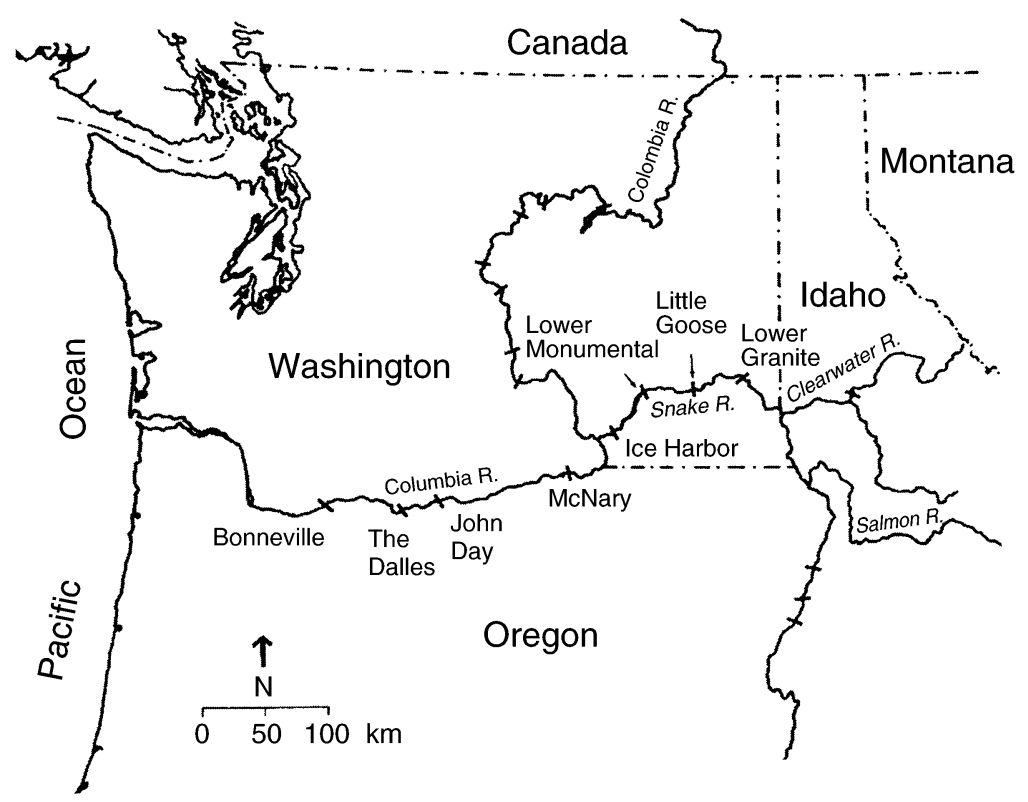

FIG. 2. Mainstem Snake and Columbia Rivers, including major hydroelectric dams. PIT-tagged fish are potentially detected at Lower Granite, Little Goose, Lower Monumental, McNary, John Day, and Bonneville Dams.

\section{Case study: Snake River spring/summer chinook salmon and steelhead}

We examined relationships between recapture and survival probabilities and fish length for juvenile chinook salmon (O. tshawytscha) and steelhead (O. mykiss) migrating out of the Snake River Basin in Idaho and Oregon, USA (Fig. 2). We chose to analyze the length phenotype because it is easily measured, reflects the developmental level of the fish (Zabel 2002), and is directly related to fish swimming ability (McDonald et al. 1998, Peake and McKinley 1998). Study fish were of both wild and hatchery origin, with the wild fish members of Evolutionarily Significant Units (ESUs, Waples 1995) listed as threatened under the U.S. Endangered Species Act. The fish were captured, PITtagged, and released (for details, see Harmon et al. 2000 and Marsh et al. 2001) at Lower Granite Dam on the Snake River (Fig. 2). We analyzed yearly release groups from 1998 to 2002, with groups separated by species and origin. Because the fish were not physically recaptured, we use the term "detection" analogously to the term "recapture" from typical capture-recapture studies. Survival and detection probabilities may vary over a season, so we analyzed fish from the 10-d period when the most fish were released per release group. The minimum sample size per release group over the 10 -d periods was 5000, which ensured enough downstream detections to conduct the analysis.

The tagged fish were potentially detected in the juvenile fish bypass systems at Little Goose, Lower Monumental, McNary, John Day, and Bonneville Dams (Fig. 1). The detectors recorded individual tag codes and uploaded them into the Columbia Basin PIT Tag
Information System (PTAGIS) operated by the Pacific States Marine Fisheries Commission (available online). ${ }^{6}$ We combined detections at the last three sites together to increase the sample size, so an individual fish had three opportunities for detection. Thus the full capture history for fish $i$ was a sequence of three digits, each digit taking on the values 1,0 , or -1 . In addition, the fork length (tip of the snout to the fork in the tail, in millimeters) of each fish was measured at tagging.

Before conducting our analyses, we performed goodness-of-fit tests to determine whether the assumptions of the CJS model were violated, which would suggest that behavioral variability existed. We reported results from the overall goodness-of-fit test, which represents a summation of several tests (Burnham et al. 1987).

We estimated parameters and $\mathrm{AIC}_{\mathrm{c}}$ values for all 32 possible models per release group. We then used the model-averaging approach to estimate model-averaged parameters and standard errors. If the effect parameter $\left(\alpha_{x}\right)$ estimate was greater than twice its standard error, this provided ad hoc evidence of a significant relationship.

Finally, we compared estimates of population survival and selection coefficients using individually varying recapture probabilities to those that ignored this information. To assess the consistency among methods, we calculated mean differences in estimates and the correlation in estimates produced by the two methods.

\section{REsults \\ Simulations}

Although we ran all combinations of parameter values (27 separate simulations), we only presented those

\footnotetext{
${ }^{6}\langle$ http://www.psmfc.org/pittag/〉
} 
TABLE 1. Simulation results for survival estimation.

\begin{tabular}{|c|c|c|c|c|c|c|c|}
\hline \multirow{2}{*}{\multicolumn{3}{|c|}{$\begin{array}{l}\text { Value of effect parameter } \\
\qquad\left(\alpha_{x}\right)\end{array}$}} & \multirow{3}{*}{$\begin{array}{l}\text { True mean } \\
\text { survival }\end{array}$} & \multicolumn{4}{|c|}{$\begin{array}{c}\text { Difference between true and estimated } \\
\text { survival }\end{array}$} \\
\hline & & & & \multicolumn{2}{|c|}{ CJS method } & \multicolumn{2}{|c|}{ Indiv. trait method } \\
\hline$p_{1}$ & $\phi_{1}$ & $\beta$ & & Mean & SD & Mean & SD \\
\hline 0.0 & 0.0 & 0.0 & 0.880 & 0.000 & 0.0171 & 0.000 & 0.0145 \\
\hline-0.35 & 0.0 & 0.0 & 0.880 & -0.001 & 0.0178 & -0.001 & 0.0152 \\
\hline 0.0 & -0.35 & 0.0 & 0.876 & 0.000 & 0.0179 & 0.000 & 0.0156 \\
\hline 0.0 & 0.0 & -0.35 & 0.881 & 0.001 & 0.0179 & 0.000 & 0.0156 \\
\hline-0.35 & -0.35 & 0.0 & 0.876 & 0.001 & 0.0178 & -0.001 & 0.0150 \\
\hline-0.35 & 0.35 & 0.0 & 0.876 & 0.000 & 0.0186 & -0.001 & 0.0152 \\
\hline-0.35 & 0.0 & -0.35 & 0.881 & -0.013 & 0.0171 & 0.001 & 0.0147 \\
\hline-0.35 & 0.0 & 0.35 & 0.881 & 0.015 & 0.0190 & 0.000 & 0.0155 \\
\hline 0.35 & 0.0 & -0.35 & 0.881 & 0.014 & 0.0193 & 0.000 & 0.0151 \\
\hline 0.35 & 0.0 & 0.35 & 0.881 & -0.014 & 0.0169 & -0.001 & 0.0144 \\
\hline 0.0 & -0.35 & -0.35 & 0.876 & 0.000 & 0.0177 & 0.000 & 0.0154 \\
\hline-0.35 & -0.35 & -0.35 & 0.876 & -0.013 & 0.0176 & 0.000 & 0.0170 \\
\hline-0.35 & 0.35 & -0.35 & 0.875 & $-\mathbf{0 . 0 1 3}$ & 0.0178 & -0.001 & 0.0164 \\
\hline-0.35 & -0.35 & 0.35 & 0.876 & 0.014 & 0.0190 & -0.001 & 0.0155 \\
\hline
\end{tabular}

Notes: Values highlighted in boldface type varied by more than 0.001 from the true survival and were considered biased. The CJS method refers to the Cormack-Jolly-Seber method, and the individual trait method refers to Eq. 2. See Methods: Simulations for a description of the simulations and Methods: Estimating population-level parameters where individuals vary for survival estimation methods.

that were necessary to establish important results (Tables 1 and 2). For all combinations of parameters, estimates of population survival and selection coefficients that incorporated individual heterogeneity were unbiased (Tables 1 and 2, Fig. 3). This indicates that the proposed methods to account for individual heterogeneity were effective.

The consequence of ignoring individual heterogeneity in recapture probabilities was much more severe for estimating selection coefficients than for estimating population survival. The distribution of selection coefficients estimated with the standard method were far more shifted away from the true value than were population survival estimates using the standard (CJS) method (Fig. 3). Although the overall magnitude of bias was relatively small using the CJS method (typically $<1 \%$ of the true survival, and the mean of the bias was less than the standard deviation; Table 1), the magnitude of bias was extremely large when using the standard method to estimate selection coefficients. When biases existed, they were more than twice as large as the true selection coefficients observed under the scenarios with trait-related survival, and the mean of the bias was $\sim 4-10$ times greater than the standard deviations (Table 2).

Population survival estimates using the CJS method were biased if trait relationships existed in both the $p_{1}$ term (first recapture probability) and the $\beta$ term (combined survival and recapture probability at the last site, Table 1). The direction of bias was dependent on the signs of the effect parameters $\left(\alpha_{x}{ }^{\prime}\right.$ s): if the signs were the same, the CJS survival estimates were negatively biased. Recall that with the CJS method, the number of individuals observed at a site is divided by the estimated recapture probability to yield an estimate of the actual number of fish alive at the sampling site. This, then, is used to estimate survival. When the signs of the effect parameters for the $p_{1}$ and $\beta$ terms were the same, the chance of observing individuals with capture history "11" (recaptured twice) was greater than expected with no relationships, leading to positively biased estimates of the recapture probability and, consequently, negatively biased estimates of survival. The opposite occurred when the signs were opposite. The presence or absence of a trait relationship with the survival parameter $\left(\phi_{1}\right)$ had no effect on the magnitude or direction of bias. The variance about the population survival estimates, regardless of method, generally increased with the number of length relationships, but the effects of the particular parameters on variance varied, with some cases of variance decreasing with added parameters. Further study is necessary to completely understand the statistical properties of the population survival estimators.

Estimates of selection coefficients were biased if a trait relationship existed in the first recapture probability term $\left(p_{1}\right)$ and it was ignored (Table 2). If the effect parameter was negative, the selection coefficient was negatively biased. This occurred because the greater probability of observing individuals with lower values of $x$ led to a negative bias in the calculation of mean $x$. The opposite occurred when the effect parameter for $p_{1}$ was positive. The magnitude of the bias remained relatively constant, regardless of the values of the parameters. Note that the value of the true selection coefficient was determined by the value of the effect parameter for $\phi_{1}$, as expected. An unexpected result with these simulations was that in the cases in which the effect term for $p_{1}$ was not equal to zero, the standard deviation about the estimated selection co- 
TABLE 2. Simulation results for estimation of selection coefficients $(\delta)$.

\begin{tabular}{|c|c|c|c|c|c|c|c|}
\hline \multirow{2}{*}{\multicolumn{3}{|c|}{$\begin{array}{l}\text { Value of effect parameter } \\
\qquad\left(\alpha_{x}\right)\end{array}$}} & \multirow{3}{*}{$\begin{array}{l}\text { True mean } \\
\delta\end{array}$} & \multicolumn{4}{|c|}{$\begin{array}{l}\text { Difference between true and } \\
\text { estimated } \delta\end{array}$} \\
\hline & & & & \multicolumn{2}{|c|}{ Standard method } & \multicolumn{2}{|c|}{ Indiv. trait method } \\
\hline$p_{1}$ & $\phi_{1}$ & $\beta$ & & Mean & SD & Mean & SD \\
\hline 0.0 & 0.0 & 0.0 & 0.001 & 0.000 & 0.0204 & 0.000 & 0.0204 \\
\hline-0.35 & 0.0 & 0.0 & 0.001 & -0.094 & 0.0200 & -0.001 & 0.0103 \\
\hline 0.35 & 0.0 & 0.0 & 0.000 & 0.094 & 0.0214 & 0.000 & 0.0105 \\
\hline 0.0 & -0.35 & 0.0 & -0.043 & 0.000 & 0.0201 & 0.000 & 0.0201 \\
\hline 0.0 & 0.0 & -0.35 & 0.000 & 0.000 & 0.0202 & 0.000 & 0.0202 \\
\hline-0.35 & -0.35 & 0.0 & -0.043 & -0.092 & 0.0204 & 0.000 & 0.0182 \\
\hline-0.35 & 0.35 & 0.0 & 0.043 & -0.093 & 0.0206 & 0.000 & 0.0146 \\
\hline-0.35 & 0.0 & -0.35 & 0.000 & -0.094 & 0.0212 & 0.000 & 0.0099 \\
\hline 0.35 & 0.0 & -0.35 & 0.001 & 0.094 & 0.0222 & 0.000 & 0.0109 \\
\hline 0.0 & -0.35 & -0.35 & -0.043 & 0.001 & 0.0200 & 0.001 & 0.0200 \\
\hline-0.35 & -0.35 & -0.35 & -0.043 & -0.091 & 0.0211 & 0.001 & 0.0236 \\
\hline-0.35 & 0.35 & -0.35 & 0.043 & $-\mathbf{0 . 0 9 3}$ & 0.0216 & -0.002 & 0.0165 \\
\hline
\end{tabular}

Notes: Values highlighted in boldface type varied by more than 0.001 from the true selection coefficient and were considered biased. The standard method is based on Eq. 4, and the individual covariate method is based on Eq. 5. See Methods: Simulations for a description of the simulations and Methods: Estimating population-level parameters when individuals vary for estimation methods.

efficients (using the individual trait method) was reduced compared to the other cases. We believe that this occurred as a result of differentially inflating observations based on their value of $x$ (Eq. 5), leading to a
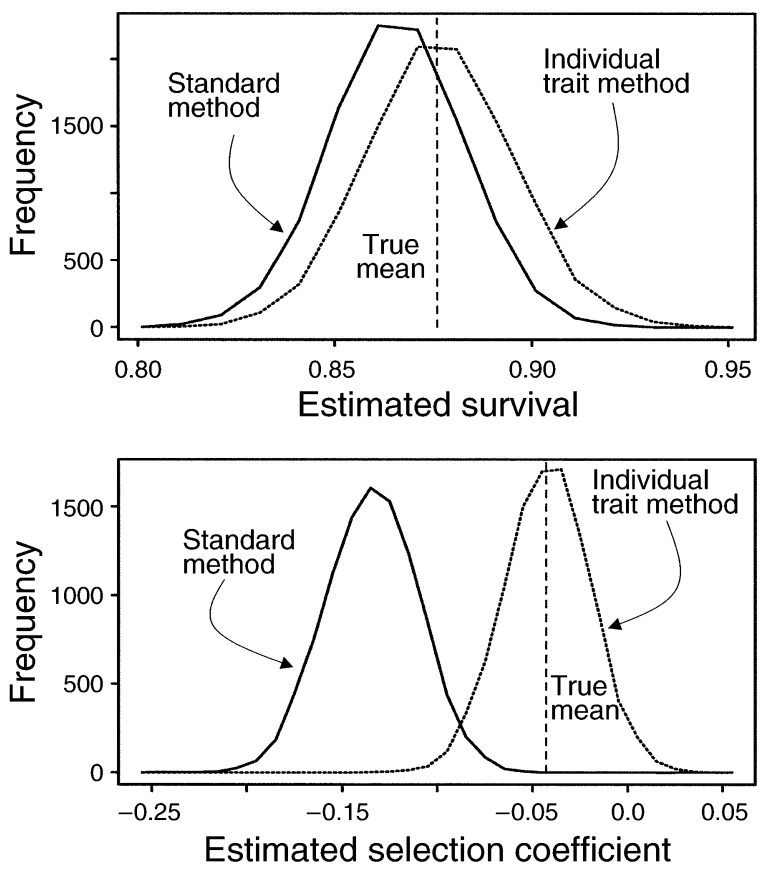

FIG. 3. Results from the simulations for estimated survival (top) and estimated selection coefficients (bottom) where negative trait relationships existed for all three model terms $\left(p_{1}, \phi_{1}, \beta\right)$. In each plot, the solid line represents the distribution of estimates when trait relationships were ignored, the dotted line represents the distribution of estimates when trait relationships were incorporated into the estimates, and the dashed vertical line represents the true mean value of survival (top plot) or the selection coefficient (bottom plot). decrease in variance. Again, further research is necessary to understand the statistical properties of the proposed selection coefficient estimator.

\section{Chinook salmon and steelhead case study}

We analyzed data from $>153000$ PIT-tagged individuals in eight release groups (Table 3 ). Distinct size differences existed among groups, with steelhead being longer than chinook salmon and hatchery fish being longer than wild ones (Table 3). In five out of eight release groups, the assumptions of the CJS model were rejected, which suggested that behavioral variability existed within the release groups. Using the model selection techniques, we selected a broad range of "best" models per release group based on their $\mathrm{AIC}_{\mathrm{c}}$ weights, ranging from one model selected for wild steelhead released in 2000 to 26 models selected for hatchery steelhead released in 1999. In no case was the CJS model selected among the suite of "best" models, further reinforcing the existence of behavioral variability.

Detection probability was related to fish length for all release groups in at least one of the sites. Overall, the model selection process chose length relationships in 11 out of 16 year-site combinations (Figs. 4 and 5, Table 4). In all cases in which a length relationship was selected, the length effects coefficient, $\alpha_{x}$, was negative, indicating that smaller fish had a higher probability of detection.

The relationship between estimated survival and fish length was not as consistent. Although the model selection process selected length relationships in 11 out of 16 year-site combinations (Figs. 4 and 5, Table 5), the direction of the relationships was variable. There was a greater tendency for positive survival-length relationships than negative ones, with eight out of 11 


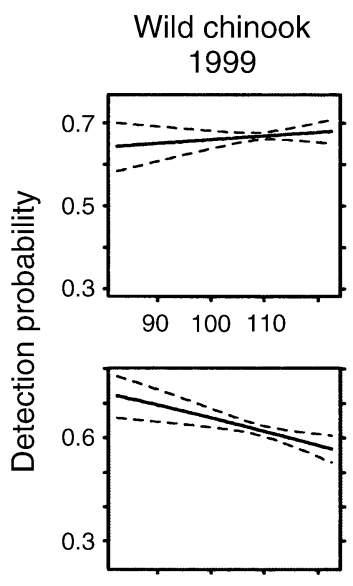

$90 \quad 100 \quad 110$

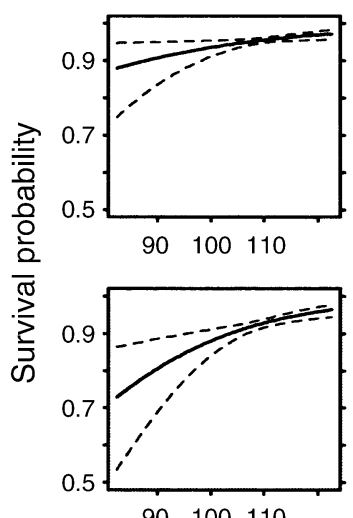

$90 \quad 100 \quad 110$

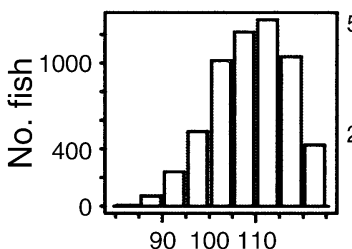

Wild chinook

2000

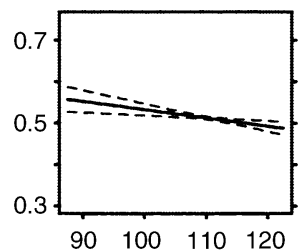

$90 \quad 100 \quad 110 \quad 120$

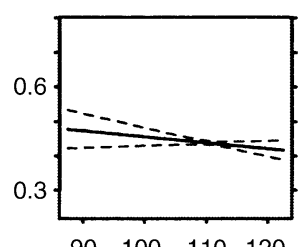

$\begin{array}{llll}90 & 100 & 110 & 120\end{array}$

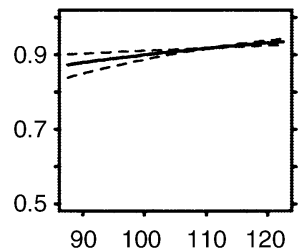

$90 \quad 100 \quad 110 \quad 120$
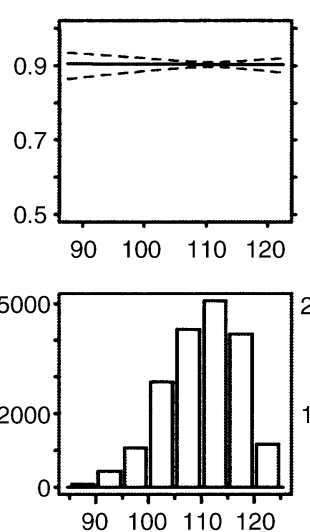

Wild chinook 2002

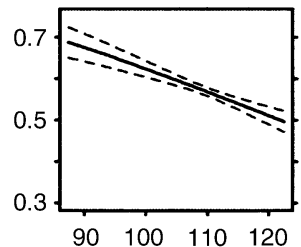

$\begin{array}{llll}90 & 100 & 110 & 120\end{array}$

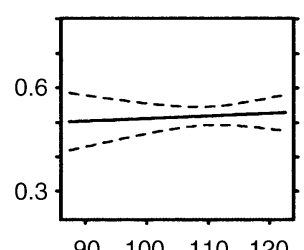

$90 \quad 100 \quad 110 \quad 120$
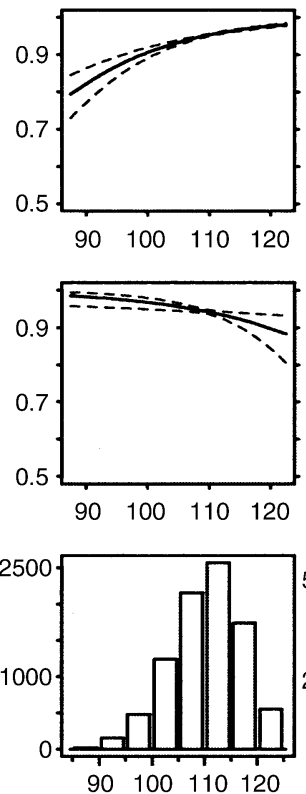

90100110120
Hatchery chinook 1998
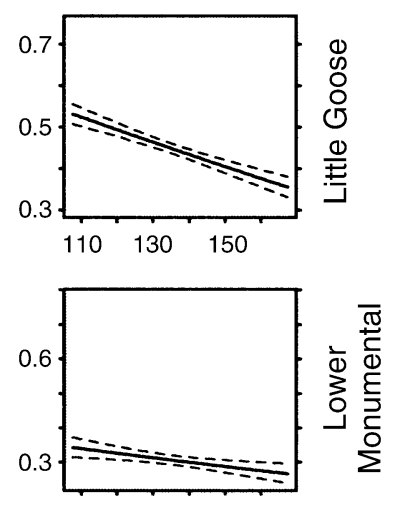

$110 \quad 130 \quad 150$
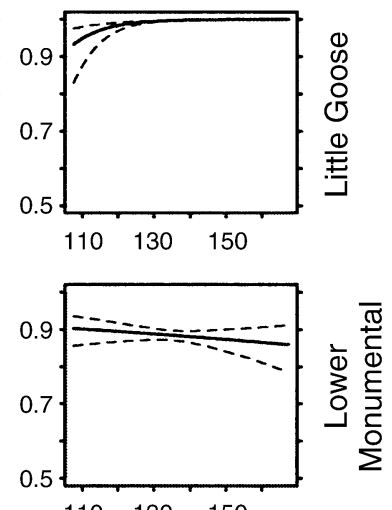

$\begin{array}{lll}110 & 130 \quad 150\end{array}$

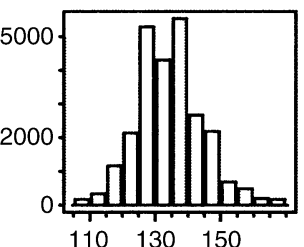

Fish length (mm)

FIG. 4. Relationships between recapture and survival probabilities and fish length by release group and recapture site based on results from Tables 4 and 5. Dashed lines show the 95\% confidence intervals about the relationships. The bottom row of plots is the distribution of lengths in each release group.

TABLE 3. Number of fish released, range of release dates, and length by species, origin (hatchery or wild), and year.

\begin{tabular}{|c|c|c|c|c|c|c|}
\hline \multirow[b]{2}{*}{ Year and fish type } & \multirow{2}{*}{$\begin{array}{l}\text { No. fish } \\
\text { released }\end{array}$} & \multirow[b]{2}{*}{ Release dates } & \multicolumn{2}{|c|}{ Fish length $(\mathrm{mm})$} & \multirow[b]{2}{*}{ GOF $P$} & \multirow{2}{*}{$\begin{array}{c}\text { No. model } \\
\text { selected }\end{array}$} \\
\hline & & & Mean & SD & & \\
\hline Wild chinook, 1999 & 5858 & 20 Apr-29 Apr & 109.3 & 8.0 & 0.8822 & 12 \\
\hline Wild chinook, 2000 & 19216 & 13 Apr-22 Apr & 110.7 & 7.5 & 0.0014 & 13 \\
\hline Wild chinook, 2002 & 8913 & 17 May-26 May & 109.8 & 6.7 & 0.0618 & 7 \\
\hline Hatchery chinook, 1998 & 25560 & 19 Apr-28 Apr & 135.1 & 10.9 & 0.0000 & 6 \\
\hline Hatchery chinook, 1999 & 32370 & 26 Apr-5 May & 137.8 & 13.6 & 0.6888 & 4 \\
\hline Wild steelhead, 2000 & 29600 & 13 Apr-22 Apr & 189.3 & 28.5 & 0.0193 & 1 \\
\hline Wild steelhead, 2002 & 13696 & 17 May-26 May & 171.2 & 18.7 & 0.0156 & 11 \\
\hline Hatchery steelhead, 1999 & 18607 & 28 Apr-7 May & 210.2 & 21.8 & 0.0035 & 26 \\
\hline
\end{tabular}

Notes: $P$ values of the goodness-of-fit (GOF) tests are presented in boldface when $P<0.05$, which indicates that the assumptions of the CJS model were violated. The number of models selected refers to the number of models retained based on their $\mathrm{AIC}_{\mathrm{c}}$ weights. 


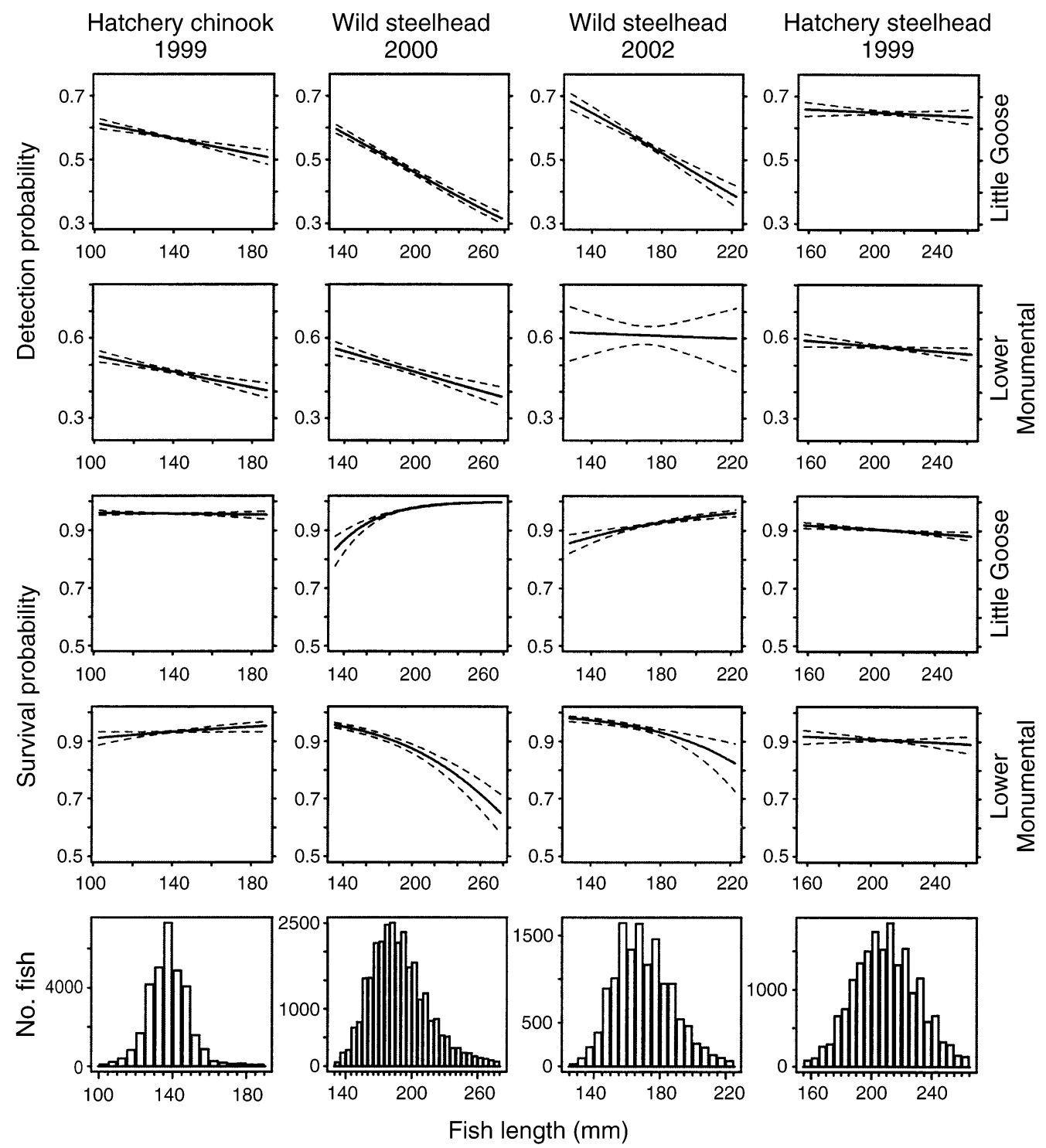

FIG. 5. Relationships between recapture and survival probabilities and fish length by release group and recapture site based on results from Tables 4 and 5. Dashed lines show the $95 \%$ confidence intervals about the relationships. The bottom row of plots is the distribution of lengths in each release group.

TABLE 4. Model-averaged parameter mean estimates for the recapture probability vs. fork length (FL, measured in millimeters) relationships by species, origin (hatchery or wild), detection site, and year.

\begin{tabular}{|c|c|c|c|c|}
\hline \multirow[b]{2}{*}{ Fish type and year } & \multicolumn{2}{|c|}{$p_{1}$ (Little Goose Dam) } & \multicolumn{2}{|c|}{$p_{2}$ (Lower Monumental Dam) } \\
\hline & $\alpha_{0}(\mathrm{SE})$ & $\alpha_{x}(\mathrm{SE})$ & $\alpha_{0}(\mathrm{SE})$ & $\alpha_{x}(\mathrm{SE})$ \\
\hline Wild chinook, 1999 & $0.702(0.0200)$ & $0.004(0.0047)$ & $0.497(0.0325)$ & $-0.017(0.0055)$ \\
\hline Wild chinook, 2000 & $0.046(0.0075)$ & $-0.008(0.0026)$ & $-0.254(0.0118)$ & $-0.007(0.0048)$ \\
\hline Wild chinook, 2002 & $0.281(0.0209)$ & $-0.023(0.0037)$ & $0.075(0.0536)$ & $0.003(0.0071)$ \\
\hline Hatchery chinook, 1998 & $-0.204(0.0242)$ & $-0.012(0.0015)$ & $-0.816(0.0324)$ & $-0.006(0.0020)$ \\
\hline Hatchery chinook, 1999 & $0.281(0.0075)$ & $-0.005(0.0009)$ & $-0.090(0.0146)$ & $-0.006(0.0011)$ \\
\hline Wild steelhead, 2000 & $-0.065(0.0170)$ & $-0.008(0.0004)$ & $-0.042(0.0236)$ & $-0.005(0.0008)$ \\
\hline Wild steelhead, 2002 & $0.201(0.0158)$ & $-0.013(0.0013)$ & $0.454(0.0700)$ & $-0.001(0.0047)$ \\
\hline Hatchery steelhead, 1999 & $0.611(0.0129)$ & $-0.001(0.0009)$ & $0.270(0.0114)$ & $-0.002(0.0009)$ \\
\hline
\end{tabular}

Note: Boldface values of the effects parameters $\left(\alpha_{x}\right)$ indicate that the estimate is greater than twice its standard error. 
TABLE 5. Model-averaged parameter mean estimates for the survival probability vs. fork length (FL, measured in millimeters) relationships by species, origin (hatchery or wild), detection site, and year.

\begin{tabular}{|c|c|c|c|c|}
\hline \multirow[b]{2}{*}{ Fish type and year } & \multicolumn{2}{|c|}{$\begin{array}{c}\phi_{1} \\
\text { (L. Granite to L. Goose) }\end{array}$} & \multicolumn{2}{|c|}{ (L. Goose to L. Monumental) } \\
\hline & $\alpha_{0}(\mathrm{SE})$ & $\alpha_{x}(\mathrm{SE})$ & $\alpha_{0}(\mathrm{SE})$ & $\alpha_{x}(\mathrm{SE})$ \\
\hline Wild chinook, 1999 & $3.034(0.0838)$ & $0.039(0.0165)$ & $2.518(0.0837)$ & $0.057(0.0156)$ \\
\hline Wild chinook, 2000 & $2.416(0.0136)$ & $0.021(0.0060)$ & $2.227(0.0396)$ & $-0.001(0.0086)$ \\
\hline Wild chinook, 2002 & $2.998(0.0390)$ & $0.074(0.0077)$ & $2.791(0.0569)$ & $-0.061(0.0232)$ \\
\hline Hatchery chinook, 1998 & $5.888(0.1910)$ & $0.118(0.0176)$ & $2.035(0.0651)$ & $-0.007(0.0077)$ \\
\hline Hatchery chinook, 1999 & $3.136(0.0121)$ & $-0.002(0.0031)$ & $2.619(0.0315)$ & $0.008(0.0039)$ \\
\hline Wild steelhead, 2000 & $3.434(0.0511)$ & $0.032(0.0031)$ & $2.124(0.0694)$ & $-0.017(0.0015)$ \\
\hline Wild steelhead, 2002 & $2.442(0.0306)$ & $0.015(0.0029)$ & $2.823(0.0761)$ & $-0.025(0.0053)$ \\
\hline Hatchery steelhead, 1999 & $2.215(0.0132)$ & $-0.004(0.0013)$ & $2.252(0.0210)$ & $-0.003(0.0029)$ \\
\hline
\end{tabular}

Note: Boldface values of the effects parameters $\left(\alpha_{x}\right)$ indicate that the estimate is greater than twice its standard error.
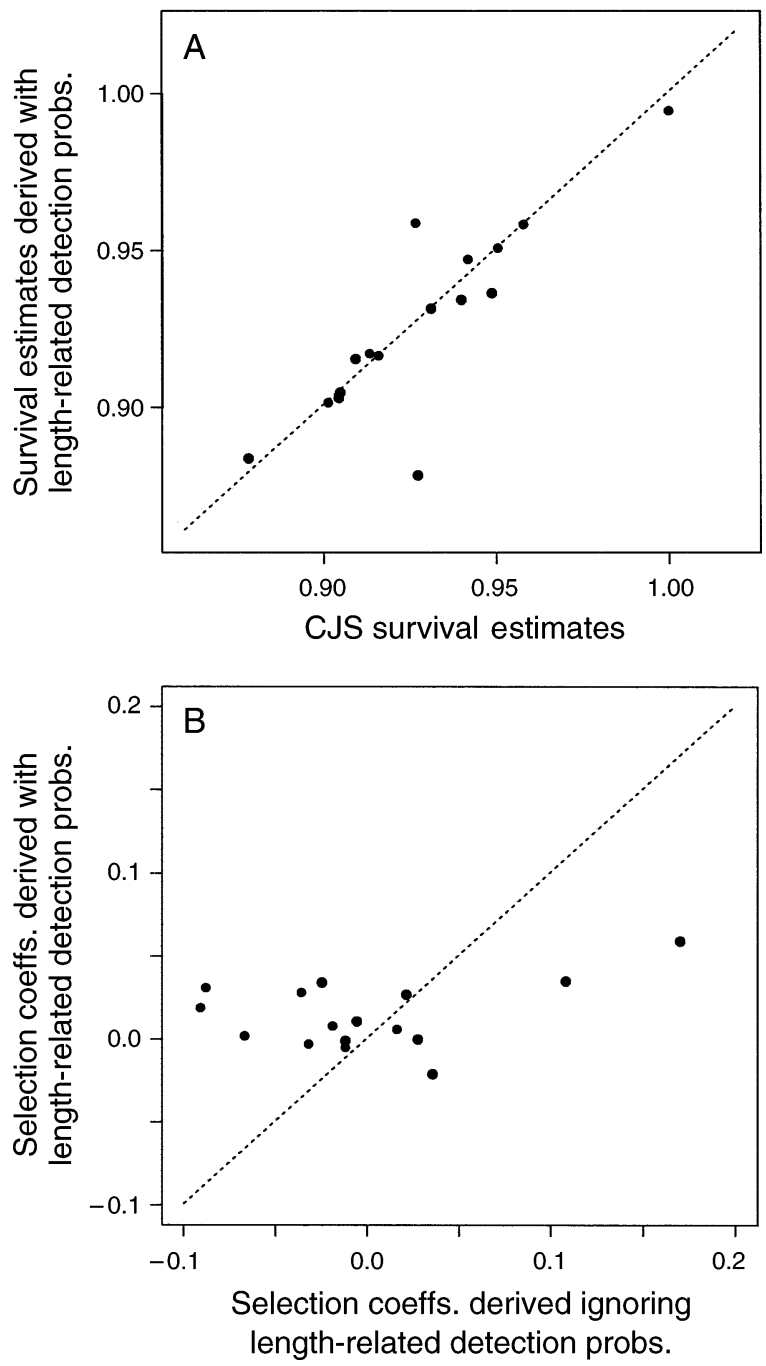

FIG. 6. Comparison of (A) survival estimates and (B) estimates of selection coefficients derived with length-related recapture probabilities to those that ignored these relationships. significant length relationships having a positive value of $\alpha_{x}$.

When we compared among methods for estimating population survival, we found a high level of correlation between methods and little evidence for bias in the CJS method when ignoring the individual trait (Fig. 6A). Survival estimates produced by the two methods were highly correlated ( $r=0.861)$, and the CJS produced survival estimates that averaged $0.1 \%$ less than those produced when incorporating individually varying recapture probabilities. One release group, wild steelhead released in 2000 , had relatively poor correlation between the two methods. When this group was removed, the correlation between the methods increased to 0.989 . This group was different from the other groups in several ways: it only had one model selected (the model with all possible length relationships) in the model selection process; the difference in $\mathrm{AIC}_{\mathrm{c}}$ between the best model and the CJS model was much larger compared to other groups $(-381.1 \mathrm{com}-$ pared to -123.5 for the next largest group); and it had relatively small standard errors for all the effect parameters (Tables 4 and 5). All of these effects lead to the conclusion that length effects were particularly strong for this release group, and that the CJS model poorly represented the survival and recapture process. We believe that this led to bias in the CJS survival estimates. We note, though, that the product of $\phi_{1}$ and $\phi_{2}$ for this release group was similar between the two methods, indicating that most of the discrepancy occurred in partitioning survival between the two river segments, not in estimating the overall survival through both segments.

When we examined selection coefficients produced by the two methods, we found striking differences (Fig. 6B). The estimated selection coefficients were poorly correlated between the methods $(r=0.365)$ and somewhat biased (mean difference of 0.015 between the two methods). The most striking result was that the selection coefficients derived from models with constant detection probabilities spanned a much greater range than those derived from models with length-related detection probabilities. Thus, ignoring differential recap- 
ture probabilities would lead to the conclusion that magnitude of selection was much greater than it actually was.

Overall, the results of the case study were consistent with the results from the simulation study. With the exception of one release group, the CJS method produced reasonable estimates of population survival that were within the range of biases produced in the simulations (Table 1, Fig. 6). Selection coefficients were extremely biased if differential recapture probabilities were ignored, and, again the range biases were consistent with those observed in the simulation study (Table 2, Fig. 6). Further, the majority of the selection coefficients estimated under the standard model were negatively biased (Fig. 6), consistent with the conclusion of the simulation study that negative trait relationships in the recapture probabilities lead to negative bias in selection coefficients.

\section{DISCUSSION}

Animal populations typically are behaviorally heterogeneous and inhabit heterogeneous environments. The same heterogeneity that leads to differential survival can also lead to differential capture rates, thus potentially obscuring population dynamics. Here we demonstrated that, with carefully planned experiments that allow for multiple recaptures of individually tagged animals, one can properly partition observed trait-related variability into survival and recapture probability components. This, in turn, allows for unbiased estimation of population survival and selection coefficients.

Probably our most striking result, obtained from both the simulation and the case study, is the demonstration of potential for extreme bias in estimating selection for phenotypic traits when differential recapture probabilities are ignored. Estimating selection for phenotypic traits is a key element of evolutionary ecology (Endler 1986), with selection coefficients routinely estimated for hundreds of taxa (Kingsolver et al. 2001). Unfortunately, many advances in capture-recapture methodology that can rectify these biases have not found their way into the evolutionary ecology literature (Clobert 1995; but see Kingsolver and Smith 1995). We note that with slight modifications, the methods that we presented here can be used to estimate more complex forms of selection such as stabilizing or disruptive selection or correlations in selection among multiple traits.

Our results indicate that population survival estimates are more robust in the face of a variety of assumption violations concerning recapture and survival probabilities, a result observed elsewhere (e.g., Lebreton 1995). This is encouraging news because CJS methodology (which ignores differential recapture and survival probabilities) is used extensively. However, an important consideration is that differential capture probabilities may result in a sample of tagged animals that is not representative of the entire population. When differential capture probabilities are combined with size-related selection, a nonrepresentative sample of individuals can produce a biased estimate of population survival, regardless of the estimation procedure.

\section{Chinook salmon and steelhead case study}

Our results clearly indicate that migrating juvenile salmonids exhibit behavioral variability. Thus, the type of analysis that we performed is warranted and can shed light on this behavioral variability. Although it is clear that seaward-migrating juvenile salmonids experience selective mortality in the mainstem Snake and Columbia Rivers, the lack of consistent pattern indicates that the selection probably arises from a variety of sources. The two primary sources of mortality for these fish are predation (by both piscivorous fish and birds) and mortality associated with dam passage. Further studies that specifically target these mortality sources are needed to elucidate these patterns.

Our analysis demonstrated a consistent negative relationship between detection probability at fish bypass systems and fish length of seaward-migrating salmonids. Size-related recapture rates can arise from two nonmutually exclusive mechanisms. First, spatial heterogeneity related to size may result in differential exposure to the trap or detection site. Second, individuals of different sizes may have differential abilities to escape the trap or detection site once they are in close vicinity. In the case of migrating juvenile salmonids, each of these mechanisms could contribute to the results that we observed, and we will examine them in more detail.

In the system that we studied, the vertical position of a fish in the water column is likely to be important in determining its probability of detection. Fish that are more surface-oriented are more likely to be diverted into bypass systems than fish swimming lower in the water column (Coutant and Whitney 2000). One key factor that influences the vertical position of salmonids is smoltification, the series of physiological, morphological, and behavioral changes that ready fish for a saltwater environment (Hoar 1976). Smolted fish are more buoyant than non-smolted ones and tend to migrate higher in the water column (Saunders 1965, Pinder and Eales 1969). We have some evidence that smaller fish may be more smolted than larger ones in the system that we studied. Gill $\mathrm{Na}^{+}, \mathrm{K}^{+}$-ATPase activity (an indicator of smoltification) was measured in juvenile wild and hatchery chinook salmon sampled from bypass systems in 2000, 2001, and 2002, and it was negatively correlated $(\alpha=0.05)$ with fish length in two of four analyses for wild fish and in four of seven analyses for hatchery fish (unpublished data, J. L. Congleton).

Our second hypothesis is that fish of different sizes react differently to flow patterns that they encounter at the face of the dam. Larger fish have longer swimming 
times-to-fatigue and greater burst-swimming abilities than smaller individuals (McDonald et al. 1998, Peake and McKinley 1998). The higher absolute burst-swimming speed and greater endurance of the larger fish may allow them to more successfully avoid guidance by diversion screens. Flow velocities approaching the screens are typically $\sim 1 \mathrm{~m} / \mathrm{s}$ (Coutant and Whitney 2000), equivalent to a velocity of 10 body lengths/s for a 100-mm fish, or 5 body lengths/s for a 200-mm fish. At these swimming velocities, the expected time to fatigue would be only a few seconds for a 100-mm salmonid (McDonald et al. 1998), but 12-15 s for a 200-mm fish (Brett 1964). Large fish would have more time to maneuver and might be able to swim around the bypass screen or sound below it.

The results of our case study have implications for the management of Columbia River Basin salmonids. PIT-tag studies are routinely used to estimate adult return rates, which are used to assess population performance. In these studies, juveniles are collected from bypass systems and are tagged, under the assumption that the collected fish represent the entire population. The tendency, demonstrated in this study, for bypass systems to divert smaller fish, on average, than the entire population, coupled with the tendency for smaller fish to return at lower rates (Zabel and Williams 2002) could lead to underestimates of population return rates. Further, studies that use bypassed fish as a treatment group and undetected fish as a control group (e.g., studies on the efficacy of transportation [Marsh et al. 2001] or examinations of the latent effects of bypass systems [Budy et al. 2002]) could produce misleading results. Williams et al. (2005) discuss this issue in much greater detail.

In summary, recent advances in tagging technology and analytical methods have enabled researchers to accurately portray survival and recapture processes in natural populations. The ability to elucidate withinpopulation behavioral variability is crucial for describing population dynamics. This, in turn, will allow us to more effectively manage at-risk populations.

\section{ACKNOWLEDGMENTS}

Charlie Paulsen, Mark Scheuerell, and Doug Dey provided valuable suggestions that greatly improved this paper. We thank Doug Marsh and his crew for PIT-tagging the hundreds of thousands of juvenile fish at Lower Granite Dam, which made this study possible.

\section{Literature Cited}

Brett, J. R. 1964. The respiratory metabolism and swimming performance of young sockeye salmon. Journal of the Fisheries Research Board of Canada 21:1183-1226.

Budy, P., G. P. Thiede, N. Bouwes, C. E. Petrosky, and H. Schaller. 2002. Evidence linking delayed mortality of Snake River salmon to their early hydrosystem experience. North American Journal of Fisheries Management 22:3551.

Burnham, K. P., and D. R. Anderson. 2002. Model selection and inference-a practical information-theoretic approach. Second edition. Springer-Verlag, New York, New York, USA.
Burnham, K. P., D. R. Anderson, G. C. White, C. Brownie, and K. H. Pollock. 1987. Design and analysis methods for fish survival experiments based on release-recapture. American Fisheries Society Monograph Number 5.

Clobert, J. 1995. Capture-recapture and evolutionary ecology: a difficult wedding? Journal of Applied Statistics 22: 989-1008.

Cormack, R. M. 1964. Estimates of survival from the sighting of marked animals. Biometrika 51:429-438.

Coutant, C. C., and R. R. Whitney. 2000. Fish behavior in relation to passage through hydropower turbines: a review. Transactions of the American Fisheries Society 129:351380.

Endler, J. A. 1986. Natural selection in the wild. Princeton University Press, Princeton, New Jersey, USA.

Hagen, N. T. 1996. Tagging sea urchins: a new technique for individual identification. Aquaculture 139:271-284.

Harmon, J. R., D. M. Marsh, N. N. Paasch, K. L. Thomas, K. W. McIntyre, B. P. Sandford, and G. M. Matthews. 2000. Research related to transportation of juvenile salmonids on the Columbia and Snake Rivers, 1999. Fish Ecology Division, Northwest Fisheries Science Center, National Marine Fisheries Service, Seattle, Washington, USA.

Hoar, W. S. 1976. Smolt transformation: evolution, behavior, and physiology. Journal of the Fisheries Research Board of Canada 33:1233-1252.

Hoffmann, A., and J. R. Skalski. 1995. Inferential properties of an individual-based survival model using release-recapture data: sample size, validity and power. Journal of Applied Statistics 22:579-595.

Hosmer, D. W., and S. Lemeshow. 2000. Applied logistic regression. Second edition. John Wiley, New York, New York, USA.

Janzen, F. J., J. K. Tucker, and G. L. Paukstis. 2000. Experimental analysis of an early life-history stage: selection on size of hatchling turtles. Ecology 81:2290-2304.

Johnson, J. B., and K. S. Omland. 2004. Model selection in ecology and evolution. Trends in Ecology and Evolution 19:101-108.

Jolly, G. M. 1965. Explicit estimates from capture-recapture data with both death and immigration-stochastic model. Biometrika 52:225-247.

Kingsolver, J. G., H. E. Hoekstra, J. M. Hoekstra, D. Berrigan, C. E. Hill, A. Hoang, P. Gilbert, and P. Beerli. 2001. The strength of phenotypic selection in natural populations. American Naturalist 157:245-261.

Kingsolver, J. G., and S. G. Smith. 1995. Estimating selection on quantitative traits using capture-recapture data. Evolution 49:384-388.

Lady, J., P. Westhagen, and J. R. Skalski. 2001. Survival under Propotional Hazards (SURPH 2.1). Columbia Basin Research, University of Washington, Seattle, Washington, USA. 〈http://www. cbr. washington. edu/paramEst/SURPH/ Manual/index.html $\rangle$

Lebreton, J.-D. 1995. The future of population dynamic studies using marked individuals: a statistician's perspective. Journal of Applied Statistics 22:1009-1030.

Lebreton, J.-D., K. P. Burnham, J. Clobert, and D. R. Anderson. 1992. Modeling survival and testing biological hypotheses using marked animals: a unified approach with case studies. Ecological Monographs 62:67-118.

MacKenzie, D. I., and W. L. Kendall. 2002. How should detection probability be incorporated into estimates of relative abundance? Ecology 83:2387-2393.

Marsh, D. M., J. R. Harmon, N. N. Paasch, K. L. Thomas, K. W. McIntyre, B. P. Sandford, and G. E. Matthews. 2001. Research related to transportation of juvenile salmonids on the Columbia and Snake Rivers, 2000. Fish Ecology Division, Northwest Fisheries Science Center, National Ma- 
rine Fisheries Service, National Oceanic and Atmospheric Administration, Seattle, Washington, USA.

Mazerolle, M. J. 2003. Detrimental effects of peat mining on amphibian abundance and species richness in bogs. Biological Conservation 113:215-223.

McDonald, D. G., W. J. McFarlane, and C. L. Milligan. 1998. Anaerobic capacity and swim performance of juvenile salmonids. Canadian Journal of Fisheries and Aquatic Sciences 55:1198-1207.

McPherson, R. J., R. W. Arnold, L. M. Armstrong, and C. J. Schwarz. 2003. Estimating the nest success rate and the number of nests initiated by radiomarked mallards. Journal of Wildlife Management 67:843-851.

Mood, A. M., F. A. Graybill, and D. C. Boes. 1974. Introduction to the theory of statistics. Third edition. McGrawHill, New York, New York, USA.

Peake, S., and R. S. McKinley. 1998. A re-evaluation of swimming performance in juvenile salmonids relative to downstream migration. Canadian Journal of Fisheries and Aquatic Sciences 55:682-687.

Pinder, L. J., and J. G. Eales. 1969. Seasonal buoyancy changes in atlantic salmon (Salmo salar) parr and smolt. Journal of the Fisheries Research Board of Canada 26:2093-2100.

Pollock, K. H. 2002. The use of auxiliary variables in capture-recapture modeling: an overview. Journal of Applied Statistics 29:85-102.

Prentice, E. F., T. A. Flagg, and C. S. McCutcheon. 1990a. Feasibility of using implantable passive integrated transponder (PIT) tags in salmonids. American Fisheries Society Symposium 7:317-322.

Prentice, E. F., T. A. Flagg, C. S. McCutcheon, and D. F Brastow. 1990b. PIT-tag monitoring systems for hydroelectric dams and fish hatcheries. American Fisheries Society Symposium 7:323-334.

Roussel, J.-M., A. Haro, and R. A. Cunjak. 2000. Field test of a new method for tracking small fishes in shallow rivers using passive integrated transponder (PIT) technology. Canadian Journal of Fisheries and Aquatic Sciences 57:13261329.
Saunders, R. L. 1965. Adjustments of buoyancy in young Atlantic salmon and brook trout by changes in swim bladder volume. Journal of the Fisheries Research Board of Canada 22:335-352.

Seber, G. A. F. 1965. A note on the multiple recapture census. Biometrika 52:249-259.

Seber, G. A. F., and C. J. Schwarz. 2002. Capture-recapture: before and after EURING 2000. Journal of Applied Statistics 29:5-18.

Skalski, J. R., S. G. Smith, R. N. Iwamoto, J. G. Williams, and A. Hoffmann. 1998. Use of passive integrated transponder tags to estimate surival of migrant juvenile salmonids in the Snake and Columbia Rivers. Canadian Journal of Fisheries and Aquatic Seciences 55:1484-1493.

Waples, R. S. 1995. Evolutionarily significant units and the conservation of biological diversity under the Endangered Species Act. American Fisheries Society Symposium 17: 8-27.

White, G. C., and K. P. Burnham. 1999. Program MARK: survival estimation from populations of marked animals. Bird Study 46(Supplement): 120-138.

Williams, J. G., S. G. Smith, R. W. Zabel, W. D. Muir, M. D. Scheuerell, B. P. Sandford, D. M. Marsh, R. McNatt, and S. Achord. 2005. Effects of the Federal Columbia River Power System on salmon populations. NOAA Technical Memorandum, NOAA-TM-NMFS-NWFSC-63, Seattle, Washington, USA. 〈http://www.nwfsc.noaa.gov/publications/techmemos/ index.cfm $\rangle$

Wright, I. E., S. D. Wright, and J. M. Sweat. 1998. Use of passive integrated transponder (PIT) tags to identify manatees (Trichechus manatus latirostris). Marine Mammal Science 14:641-645.

Zabel, R. W. 2002. Using "travel time" data to characterize the behavior of migrating animals. American Naturalist 4: 372-387.

Zabel, R. W., and S. Achord. 2004. Relating size of juveniles to survival within and among populations of chinook salmon. Ecology 85:795-806.

Zabel, R. W., and J. G. Williams. 2002. Selective mortality in chinook salmon: what is the role of human disturbance? Ecological Applications 12:173-183. 